\title{
La concepción del Estado conservador: Bartolomé Herrera y su proyecto constitucional de 1860
}

\author{
The conception of the conservative State: Bartolomé Herrera \\ and his constitutional project of 1860
}

José Carlos Jiyagón Villanueva

Universidad de Lima

\section{RESUMEN}

El presente artículo nos remite a la construcción del Estado peruano, destacando la figura de Bartolomé Herrera, una de las voces políticas del siglo xix en el Perú. Sus propuestas plantean un Estado que mantenga el orden y esté debidamente organizado para poder sortear los males de la anarquía, que ha golpeado al país desde el proceso de la Independencia. A raíz de la convocatoria del Congreso de 1860, que se encargó de elaborar una nueva Constitución, el obispo Herrera presentó un proyecto constitucional con el objetivo de fortalecer la investidura del Poder Ejecutivo y limitar el excesivo poder que tenía el Legislativo. En esta propuesta se busca consolidar la "soberanía de la razón" para la construcción del Estado; por ello, resulta interesante cómo concibe a la ciudadanía y los derechos constitucionales.

Palabras clave:

proyecto constitucional, Constitución de 1860, poderes del Estado, garantías constitucionales

\section{ABSTRACT}

This article refers us to the creation of the Peruvian State, standing out the figure of Bartolomé Herrera, one of the political voices of the nineteenth century in Peru. His proposals presented a state that kept everything under control, and was duly organized in order to circumvent the evils of anarchy which had struck the country since the independence process. Following the call of the Congress of 1860, which was responsible for elaborating a new constitution, bishop Herrera presented a constitutional project with the aim of strengthening the investiture of the Executive Branch and limiting the excessive power of the Legislative Branch. These proposals sought to consolidate the "sovereignty of reason" for the creation of the state. Hence, it is interesting the way he conceived citizenship and constitutional rights.

Key words:

constitutional project, Constitution of 1860, branches of the state, constitutional guarantees 


\section{Introducción}

a a llegada del bicentenario es una invitación a reflexionar sobre cómo el país ha estado construyendo, a largo plazo, la institucionalidad; en ese sentido, es clave entender cómo fue insertándose en la modernidad, dejando poco a poco la herencia colonial. Por eso, la construcción de las instituciones en la década de 1850 es clave, ya que se empiezan a sentar las bases de la modernización del Perú y a construir lo que la Independencia había augurado. Uno de los hombres que promueve el fortalecimiento de las instituciones es Bartolomé Herrera, quien a través de sus propuestas intenta cumplir con dicha promesa. El año de 1860 marca el inicio de un nuevo periodo constitucional en el país, tras otro de tensiones políticas que culminó con la victoria de Castilla en alianza con los sectores conservadores; que termina imponiendo una nueva reforma constitucional, en la que las propuestas de Herrera serán presentadas ante el Congreso.

Durante la década de 1850, el país fue llevado a la senda de la modernidad, y se produjeron reformas que, bajo el impulso de los intelectuales liberales, buscaban llevarlo hacia la era del progreso. Desde el plano político, económico, administrativo, el Perú estaba encaminado hacia la construcción de un Estado orgánico, que mantuviera las bases sociales heredadas de la Colonia.

\section{Contexto}

El proyecto constitucional que presentó el obispo ultramontano Bartolomé Herrera pretendía cambiar la tan criticada carta de 1856. En la justificación de su proyecto, establece que el sentido del deber es el que lo mueve, pues desea que el país salga del caos. Herrera, desde su nombramiento como diputado por la provincia de Jauja, había manifestado su interés por impulsar la reforma constitucional. Demás está decir que también se encuentra en su persona el deseo de proteger los derechos de la Iglesia, que han sido duramente afectadas por la Constitución de 1856. Durante el mes de julio de 1860 aparece el periódico de raigambre católica llamado El Progreso Católico, que prosigue la línea de EI Católico; el cual trata de proteger los intereses del catolicismo para que no se vea afectado por la nueva carta constitucional. En él, Herrera comenta:

Probaremos que el catolicismo es a la sociedad, es a la patria lo que el alma al cuerpo; que sus doctrinas respiran los más sanos principios políticos y sociales, y que, por esto mismo, sus leyes son el más sólido fundamento de las constituciones y de los códigos civiles: Con nuestro Católico hemos defendido la doctrina católica. Con nuestro Progreso Católico sostendremos que el catolicismo es la última y más acabada fórmula de perfectibilidad y bienestar social. (p. 1)

El proyecto de Herrera está marcado por ideales conservadores y ultramontanos; por ello, intenta evitar que la nueva Constitución se convierta en una fe de erratas de la Constitución de 1856, pues no solamente deben cambiarse los temas controvertidos de aquella carta; como la pena de muerte, la elección de los senadores, la contradicción de la autoridad presidencial. Debe haber propuestas acordes a la realidad; por esta razón, el obispo plantea la vigencia e importancia del régimen presidencialista, que en un país como el Perú es necesario establecer, ya que el Congreso, a pesar de todas sus buenas intenciones, no se encuentra a la altura de las circunstancias. Bartolomé Herrera creía que un Legislativo fuerte no contribuía a la gobernabilidad del país.

En ningún momento, el orden republicano del país debía ser alterado por el cambio constitucional, muy necesario desde el punto de visto de los conservadores, tal como mencionaba Bartolomé Herrera (1860):

\begin{abstract}
Salvando los principios de nuestro sistema de gobierno, y sin perder de vista nuestros más importantes y más arraigados hábitos constitucionales, se han de quitar los estorbos que la convención puso a la recta aplicación de aquellos, y la violenta innovación que quiso hacer en estos. (p. VI)
\end{abstract}

Estas palabras demuestran la preocupación de Herrera por cambiar la Constitución de 1856, la cual era vista como la fuente de los trastornos políticos; por ello, debía elaborarse una nueva carta magna en donde se establezcan los ideales del orden. Su propuesta constitucional fue presentada para que pueda ser leída por los diputados del Congreso de 1860; especialmente por la comisión de Constitución del Congreso, encargada de elaborar la nueva Constitución.

Las pretensiones del obispo Herrera consistían en mantener los privilegios que gozaba la Iglesia antes de la Convención liberal de 1855, de allí que sus propuestas apunten a defender el catolicismo. Asimismo, trata de impedir que se establezcan otros cultos en el país; pues, según él, debe privilegiarse el culto católico, el que profesa la población. Defiende la idea que los acuerdos firmados entre el Perú y la Santa Sede deben partir del espíritu del Concordato: aquí se aprecia los intereses de los sectores ultramontanos. 
Por esa situación, una de las primeras propuestas que Herrera plantea es sobre quiénes deben ser considerados peruanos; en ese sentido, sigue el camino esbozado por la primera Constitución, que establece que uno es peruano desde que hereda la condición, sea por voluntad o sea por naturalización. Pero la parte más llamativa de su propuesta es que el acceso a la naturalización también debía fundamentarse en la religión, su respeto y la obediencia de las leyes. Para él, estas son condiciones necesarias para que los individuos puedan integrarse a la comunidad peruana; es decir, la principal variable que debe considerarse para ser peruano es el criterio religioso.

\section{La soberanía de la inteligencia y la ciudadanía en su proyecto constitucional}

En su obra Proyecto de reforma constitucional, Bartolomé Herrera establece los parámetros sobre el ejercicio de la ciudadanía y considera las siguientes situaciones: tener la condición obligatoria de ser vecino de un lugar; además, contar con el siguiente estado civil: casado o viudo, o haber cumplido los 21 años de edad, así como estar inscrito en el registro de ciudadanos. Estos requisitos pretenden que los individuos que ejerzan la ciudadanía sean conscientes de sus deberes hacia su comunidad, lo cual parte de la tradición corporativa planteada por los conservadores (Del Águila, 2013, pp. 154-155). De igual modo, en el proyecto presentado establece las condiciones que llevan a perder la ciudadanía; así, encontramos las siguientes ideas:

- Por falta de inteligencia, en la que apunta hacia los analfabetos; ellos debían ser excluidos. Esta idea iba en consonancia con su propuesta de la soberanía de la inteligencia. La exclusión de los analfabetos, fundamentalmente, recaía en la masa indígena y volvía a poner en cuestión el grado de participación de estos en la política. También estaban excluidos quienes no tenían una salud mental adecuada.

- Por falta de libertad; aquí se refería a la clase trabajadora de la época: jornaleros, sirvientes, criados, y sostenía que no debía formar parte de la ciudadanía. En esta idea se aprecia, con suma claridad, la concepción de la modernidad tradicionalista de Herrera, quien deseaba que esas masas siguieran dedicadas al trabajo y no a la participación cívica.

- Por presunción de falta de probidad; en la que alude a los deudores, los procesados judiciales, los vagos; también, a los que compran o venden votos en las elecciones.

En estas circunstancias, no hay duda de las posturas de Herrera sobre la ciudadanía, dado que plantea quiénes deben ser excluidos, y retoma su discurso conservador sobre la soberanía de la inteligencia. A todo esto agrega que las personas que van a participar del poder deben ser personas con un sentido de amor por la patria y de justicia (Espinoza, 2010, pp. 258-259).

Al tratar el tema de las garantías constitucionales, Bartolomé Herrera las divide en tres partes. En primer lugar, menciona las garantías de las personas, donde reitera el hecho de la abolición de la esclavitud, señalando que en el territorio peruano nadie es esclavo. El principio de la igualdad está presente también en su proyecto, al rechazar los privilegios que existen en algunos sectores de la sociedad civil y considerar que los reconocimientos deben basarse en los talentos y virtudes de las personas. Asimismo, plantea que se defienda el honor y la vida, la inviolabilidad del domicilio, la garantía de reclamar las infracciones constitucionales y la de acceder a la instrucción primaria gratuita, así como el fomento de establecimientos que impartan instrucción.

La segunda garantía constitucional que posee el individuo es la libertad de acción, en donde debe asegurarse la libre circulación por el territorio, la libertad de imprenta que permite circular las ideas, siempre y cuando no se afecte a terceros; también debe gozarse de la libertad de industria y de todo trabajo que no colisione con los intereses de la religión, la moral, la seguridad pública. De igual manera, queda garantizado el derecho a la asociación, una idea que Herrera promovió en el Senado. La idea de tener asociaciones no era novedosa, pero permitía que las corporaciones sociales se articulen mejor en un Estado que trata de implantar reformas que lleven a la modernización.

La tercera garantía constitucional está referida a la propiedad, la cual es inviolable y es un bien preciado dentro del liberalismo burgués; aquí se intenta adaptar a nuestra realidad. Es preciso notar que en este punto se pueden encontrar reminiscencias de la tradición, puesto que todavía se acepta que los bienes pueden ser expropiados o usurpados por el Estado. En cuanto a los cargos públicos, también se encuentra algo de esa mentalidad tradicional, que considera que los empleados públicos con títulos conforme a la ley no pueden ser destituidos, salvo por mandato judicial o presidencial. Esta visión, claramente tradicionalista, había sido criticada por los liberales de la Convención de 1855. 


\section{Los poderes de Estado en la concepción de Bartolomé Herrera}

Al escribir sobre las instituciones del Estado, Bartolomé Herrera expresa la visión de su entorno ideológico, en el cual la organización del Estado es fundamental. Él es un ferviente creyente de la división de poderes y del constitucionalismo; de allí que plantee propuestas para la debida organización de los poderes del Estado.

\subsection{La visión sobre el Poder Legislativo}

Empieza mostrando un particular interés sobre el Congreso, el cual debía organizarse de manera bicameral, para evitar los errores que había cometido el anterior Congreso unicameral. En su propuesta se encuentran recomendaciones sobre cómo deben realizarse las sesiones legislativas, evitando el entrampamiento por las indefiniciones que llevan a que el Parlamento sea criticado. Por esa situación, plantea que las sesiones ordinarias deben tener una duración de 100 días útiles y que las extraordinarias no deben tener una duración fija de tiempo. Además, propone que las propuestas legislativas sean aprobadas por mayoría en ambas cámaras; asimismo, se prevé que, si no hay una mayoría reunida para aprobar alguna norma, solo entonces se requeriría más de un tercio de los votos en ambas cámaras. Con estas propuestas, piensa que se puede evitar el entrampamiento en la aprobación de leyes.

El proyecto estipula también que los congresistas pueden desempeñar algún cargo en el Ejecutivo, pero con el aval del Congreso de la República. Como piensa que la renovación parcial del Congreso es parte importante en la construcción de la estabilidad política, plantea que el Senado se renueve por tercios, cada cuatro años. En el caso de la Cámara de Diputados, cree que debe hacerlo cada dos; con lo que se asegura que los diputados asistan a dos legislaturas ordinarias. Para difundir sus labores, el obispo recomienda la publicación de las obras en un diario, con la finalidad de construir opinión en la población letrada. Con estas medidas se esperaba que el Poder Legislativo renovase sus cuadros políticos, contribuyendo a la estabilidad de la República, y que la ciudadanía conociera las funciones del Congreso.

En el proyecto de Herrera, la Cámara de Diputados es de relativa importancia, pues debe representar los diversos intereses de las diferentes regiones del país, además de discutir las nuevas ideas que llegasen al país para que puedan difundirse o bloquearse, ya que la población está expuesta a los peligrosos sesgos ideológicos del exterior, como el socialismo, el cual era considerado como una amenaza para el orden social. En cuanto al número de integrantes, este proyecto señala que debe estar de acuerdo a lo estipulado por la ley, es decir, por cada provincia debe haber un representante, y en territorios con poblaciones que tienen un número superior a los cincuenta mil habitantes debe elegirse un representante.

De igual modo, reitera que los requisitos para ser elegido, además de la edad, que debe ser superior a los 28 años de edad, es poseer una residencia fija y tener una renta superior a los 800 pesos mensuales. Se señala también que los representantes del Ejecutivo están imposibilitados de ejercer el cargo de legislador. La posibilidad de tensión entre el Ejecutivo y el Senado debía ser evitada; por ello, la Cámara de Diputados debía servir como mediadora entre ambos poderes del Estado.

Las innovaciones que presenta Herrera con respecto al Congreso se refieren a la Cámara de Senadores, señalada como la parte más importante del Legislativo. Esta cámara debía estar integrada por treinta senadores y sus sesiones debían realizarse todo el año; con ello se esperaba un trabajo continuo y constante que contribuyera a la construcción de una sociedad civil que busque el ansiado bien común. En la propuesta de Herrera, el Senado debía ser considerada una institución corporativa, insertándose en ella a los elementos más destacables de la sociedad. El interés del obispo radica en la funcionalidad de sus representantes, que debe ser en beneficio del país; por ello, los senadores deben ser escogidos de la siguiente forma:

\begin{abstract}
De la carrera política: los que hayan servido algún ministerio de Estado, legación, prefectura u oficialía mayor de ministerio. Del rubro de la hacienda, de la magistratura, del clero, del ejército y la armada, los que hayan sido diputados (3 veces), de las profesiones científicas (profesores con 20 años de servicio, rectores y vicerrectores), los propietarios de predios (con una renta de 4 mil pesos), los dueños de minas, los comerciantes (que posean un capital de 200 mil pesos), con ello se colocaban parámetros que solo una serie de sectores podrán alcanzar. (Herrera, 1860, pp. 21-22)
\end{abstract}

Las funciones del Senado eran aprobar los tratados internacionales, enviar a la Cámara de Diputados la lista de senadores elegibles, aprobar o rechazar las propuestas del Ejecutivo con respecto a la promoción de generales, solucionar los conflictos de intereses entre el 
presidente, la Cámara de Diputados y el Poder Judicial. Ante la Cámara de Senadores debía juramentar el presidente de la República, y esta Cámara concedía también los indultos a petición del presidente. Ello muestra la importancia que Herrera le concedía a la Cámara de Senadores, lo cual se ratificaba con otra facultad: la suspensión de las garantías constitucionales de la persona, como la inviolabilidad del domicilio, el apresamiento sin el debido proceso, la ilegalidad del destierro y la libertad de imprenta. Todo ello, claro está, en el caso que la República pasara por un grave periodo de inestabilidad política que ocasione una crisis social. En esas circunstancias, se prefería la recuperación del orden; los conservadores ya habían proclamado que la libertad no debía conducir al desorden ni al caos (Jamanca, 2015, pp. 208-209). En tal sentido, el Senado era la Cámara pensante del Legislativo; por ello, era clave su conformación. Aquí encontramos enmarcada las tesis de Herrera acerca de la soberanía de la inteligencia.

Las labores del Senado eran analizar y estudiar las leyes; por ello, debían velar por el orden, y si existía alguna norma en contra de los intereses de la República, el Senado debía inhabilitarla. Además, tenía la potestad de elegir al presidente de la República, en caso de que no se cumplan las disposiciones que se establecerían en la Constitución (Herrera, 1860, p. 26). En el pensamiento de Herrera sobre el Senado está presente el poder conservador; esta Cámara se convertiría en el guardián de la estabilidad política del país. Finalmente, cuando se promulgó la carta constitucional de 1860, el Senado no tendría varias de las atribuciones mencionadas en el proyecto de Herrera, solo se mantuvo la competencia del Senado en arbitrar las discrepancias entre el Ejecutivo y el Poder Judicial (Corte Superior y Suprema) y de vacar la investidura presidencial'.

\subsection{La visión sobre el Poder Ejecutivo}

En cuanto el Poder Ejecutivo, las propuestas no son muy diferente a las otras; es encargado al presidente de la República, quien debe cumplir una serie de requisitos, como haber sido expresidente de la República, senadory consejero de Estado. El Congreso debe elaborar una lista sobre quienes pueden ser los candidatos presidenciales, quienes serán elegidos por los colegios electorales, según consta en la ley. El presidente deberá alcanzar una mayoría absoluta; en caso de no alcanzarla, el Congreso sería el encargado de elegir al presidente; en caso de empate en ambas Cámaras, la decisión final la tendrá el Senado. Al mismo tiempo, debe elegirse un vicepresidente que se encargue de la presidencia en caso de ausencia del presidente, y los mismos requisitos para la presidencia se aplican al vicepresidente. El periodo de gobierno del presidente debe ser de seis años, y puede reelegirse; el proyecto de Herrera establece que quienes ya han ejercido el cargo pueden presentarse a la candidatura presidencial.

Entre las atribuciones otorgadas al presidente, se encuentran: promulgar y hacer cumplir las leyes, las garantías constitucionales; tomar parte en la conformación de las leyes; proponer los consejeros de Estado; velar por la seguridad de las rentas de la nación; velar por la administración de la justicia, nombrando vocales de los tribunales Supremo y Superior, a jueces de primera instancia y fiscales. Con estas propuestas, Bartolomé Herrera pretende una injerencia del Ejecutivo en el Poder Judicial; esta norma no sería aplicada en la Constitución de 1860 por la conflictividad que traería. Asimismo, se le otorga el mando supremo de las Fuerzas Armadas, nombra a los generales y almirantes, declara la guerra - con decreto del Congreso-, celebra los convenios internacionales, nombra y remueve a los ministros de Estado; en fin, el proyecto de Herrera vuelve a instaurar un presidencialismo fuerte y vigoroso.

Dentro del aparato administrativo burocrático, los ministros también deben cumplir sus funciones; la firme certeza de que debían servir al Estado hizo que el obispo diera sus recomendaciones, las cuales se desprenden de las anotaciones: "los ministros de Estado autorizan, con su firma, los actos administrativos del presidente" (Herrera, 1860, p. 42). Se fijan también los requisitos que debían tener estos servidores del Estado: los mismos que para ser senador; es decir, mayor de 28 años, rentas fijas superiores a 800 pesos y capacidades notorias. Los ministros nombrados se reúnen en el denominado Consejo de Ministros; además, deben velar por el cumplimiento de las órdenes del presidente y del Congreso. Estos funcionarios son parte de un engranaje, en el que deben cumplir su labor, que es la de secundar las disposiciones del presidente. También, están obligados a asistir al Congreso y rendir cuentas, y contestar las interpelaciones que le podía realizar la Cámara de

1 El artículo 65 de la Constitución de 1860 establece los siguiente: “El Presidente de la Republica no podrá ser acusado durante su periodo, excepto en los casos de traición, de haber atentado contra la forma de Gobierno, de haber disuelto el Congreso, impedido su reunión, o suspendido a la Cámara de Senadores. 
Diputados. Los límites de sus funciones son precisos, ya que se espera que sus obligaciones sean cumplidas, como servidores del Estado.

La propuesta novedosa que encontramos en el escrito de Herrera es el establecimiento del "Consejo de Estado", el cual tendría la finalidad de ilustrar al gobierno de turno y recomendar medidas administrativas certeras, que tengan proyección en el territorio nacional. Estaría integrado por los siguientes personajes: el vicepresidente de la República, los expresidentes, los ministros de Estado, el arzobispo de Lima, el presidente de la Corte Suprema, el director general de Hacienda y nueve consejeros elegidos por el Congreso de la República. Las funciones que desarrollaría este organismo son:

1. Prestar o negar su acuerdo al presidente de la República, cuando se lo pidiere, y en todo caso lo que exija la Constitución, para que pueda ejercer algunas de sus atribuciones.

2. Darle dictamen, siempre que lo pidiere.

3. Proponer al presidente de la República, arzobispos y obispos [...], y para vocales de los tribunales de justicia, jueces, fiscales y agentes fiscales.

4. Representar al presidente sobre lo ilegal, anticonstitucional o perjudicial a la nación, de sus actos, de los de sus ministros, y demás funcionarios públicos; y sobre la necesidad de remover a estos con arreglo a la ley. (Herrera, 1860, p. 48)

Este organismo sería la institución consejera de más alto grado, que asesoraría al presidente con la experiencia que cada integrante había tenido en el desempeño de sus cargos. Sus capacidades y experiencias debían servir para lograr una gestión más eficaz del gobierno. Los sucesos acontecidos en la década de 1850 reforzaron la idea de que las personas más capaces debían estar en la toma de decisiones. El orden conservador está presente en su discurso.

\subsection{El Poder Judicial ysus observaciones}

El Poder Judicial también está incluido en la propuesta de Herrera. Se concentra en la administración de la justicia, que debe ejercerse desde distintos fueros; Cortes Comunes, Suprema, Superior, Primera Instancia, de Paz. Las atribuciones judiciales también se pueden ejercer desde los tribunales de la Iglesia, militares, de comercio, en fin; los fueros corporativos mantendrían a su criterio la administración de justicia. Herrera recomienda que los juicios sean públicos, respetando las instancias de los distintos tribunales. El proyecto contempla también la posibilidad de denunciar a los jueces por prevaricato, cohecho o procedimiento ilegal; esto se establece porque estos funcionarios no se someten al juicio de residencia y tampoco pueden ser destituidos, salvo por la intervención del presidente de la República, quien sí tenía dicha potestad.

\section{La administración del Estado según Herrera}

La organización administrativa de la República es otro de los temas que propone Herrera, a diferencia de la Constitución de 1856, que impulsaba la descentralización política, ya que restableció las juntas departamentales y las municipalidades. El proyecto contempla que la división de la república debe darse en unidades administrativas, como departamentos, provincias y distritos. Las autoridades designadas, como el prefecto y el subprefecto, representan y defienden los intereses del Ejecutivo; estos, a su vez, designan a los gobernadores, y estos a los tenientes gobernadores.

Todo el aparato administrativo depende del presidente de turno, situación que ya venía dándose en las Constituciones anteriores, las cuales otorgaban una fuerte presencia al Ejecutivo. Esta situación fue aprovechada por Castilla, pues ello le permitió forjar sus redes clientelistas con las élites provincianas. El general Castilla aprovechó estas circunstancias para forjar el Estado patrimonialista, y con la ideología de Herrera se pudo recomponer la clase dirigente del país (Mc Evoy, 1997, pp. 24-28). La idea clave es el orden, que va de la mano con la fortaleza del poder presidencial; el concepto de descentralización no es apreciado de manera positiva por el discurso conservador; por ello, las autoridades provinciales deben estar sujetas al Ejecutivo. Acerca de los municipios, presenta la siguiente idea:

\begin{abstract}
Las municipalidades no son cuerpos representativos, sino simplemente administrativos. Están subordinadas, conforme a la ley, al Poder Ejecutivo y al Congreso, en cuanto es necesario para que cumplan ellas sus deberes en bien de los pueblos, y para mantener la unidad del Estado. Su principal destino es evitar, por su intervención en el cumplimiento de las leyes onerosas, y en el de las medidas de policía toda molestia inútil. (Herrera, 1860, p. 53)
\end{abstract}

En tal sentido, es destacable que los planteamientos de Herrera obedecen al pensamiento de los grupos conservadores limeños sobre la descentralización, la cual está asociada a la idea del desorden y caos. Por ello, las municipalidades no son bien apreciadas. 
El proyecto también establece la situación de la defensa nacional. Para desarrollar tal política, se presenta la idea de“la fuerza pública", que estaría integrada por el Ejército, la Armada, la Guardia Nacional y la Policía. La función de ellos estaría destinada a la protección del Estado y del territorio nacional, con el objetivo de mantener el orden en el país; además, defender las leyes de la República ante cualquier intento de desacato y desafío por parte de cualquier elemento del país. Dentro de la construcción de la institucionalidad, se propone la subordinación de los militares a los gobiernos, lo que implica acatar las órdenes de las autoridades sin vacilación.

La historia republicana del siglo xIx ha sido testigo de la desobediencia de la milicia, situación que ha dado lugar a la "espina" del militarismo, criticado por todos los sectores de la sociedad, pues era acusado de ser el causante del caos. El proyecto establece que el número de las fuerzas públicas, los nombramientos, el aumento de sus fuerzas y el reclutamiento, sean señalados por las leyes. Con ello se pretende un eficiente control de la milicia, idea que estaba en el planteamiento de los conservadores y que coincide con la de los liberales; pues para conseguir la modernización de la República, era necesario contener los excesos del militarismo, que tanto daño habían ocasionado al país.

\section{La reforma de la Constitución}

El capítulo final del proyecto está dedicado a la modificación y reforma de la Constitución; allí establece que en cada legislatura ordinaria se pueden realizar observaciones a la Constitución. Este mecanismo permitiría apreciar las fallas que se dieron en el documento constitucional, posibilitando su reforma y mejoramiento. El planteamiento no era novedoso, pues seguía el camino trazado por la Constitución de 1956, que ya planteaba que, para poder reformarla, era necesaria la aprobación, en dos legislaturas ordinarias, por dos tercios de cada Cámara, y que, además, debía contar con la autorización presidencial, en acuerdo con el Consejo de Estado. Con ello se trata de instrumentalizar los mecanismos necesarios para impulsar la reforma constitucional.

Una última idea que plantea el proyecto es establecer cómo se produciría el traspaso constitucional al nuevo Congreso y Gobierno. Una vez instalado el nuevo Parlamento bicameral, se establecía que debía ceñirse a lo señalado por la nueva Constitución. Se plantea que debe derogarse toda norma que contraviniera la Constitución vigente; con ello, se pretendía derogar las leyes liberales que se oponían al nuevo orden conservador que había triunfado en 1858. Lo destacable del proyecto constitucional de Bartolomé Herrera es su concepción del régimen corporativo; el cual, como se mencionó, debía representar a los mejores sectores de la sociedad. La lucha de Herrera también se daría en el campo eclesiástico, pues insistía en la necesidad de firmar un Concordato con la Santa Sede; aprovechándose, para ello, el aparato propagandístico católico, con el firme interés de promover dicho acuerdo.

Finalmente, cuando se presentó la Constitución de 1860, el presidente del Congreso, el general Mendiburu, declaró que este documento era una expresión de la soberanía de los pueblos, que conservaba las libertades públicas y los derechos del hombre en la sociedad, y recalcó que en la elaboración de la Constitución no había influencia de sectores del fanatismo ni del radicalismo (Pareja, 1943, p. 132). La Constitución le devolvió al Ejecutivo varias de las atribuciones de las que lo despojó la Constitución de 1956; se determinó que el Congreso sería bicameral; y se ratificó algunas reformas liberales, como la supresión de los fueros y privilegios. De esta manera, empezó la existencia de la Constitución que mayor tiempo de vigencia ha tenido en la vida republicana.

\section{A modo de conclusión: el ultramontanismo y su respuesta}

La aparente derrota de los sectores liberales, con el cierre de la Convención Nacional de 1855 y la clausura del Congreso Extraordinario de 1858, permitió a los sectores conservadores, especialmente los eclesiásticos —denominados ultramontanos-, impulsar la firma del Concordato con la Iglesia Católica Romana para proteger la posición de la Iglesia peruana frente al Estado, que había sido golpeada por los sectores liberales regalistas. Por ello, el obispo Bartolomé Herrera informó al nuncio apostólico en Bogotá sobre la situación favorable para la firma de dicho acuerdo (Iberico, 2013, p. 72)

La situación no sería muy distinta en 1858, ya que el Congreso Extraordinario ratificaría muchas de las reformas liberales que ya había establecido la Constitución de 1856; sin embargo, la coyuntura política benefició a lo ultramontanos, pues nuevamente, en el bienio 1858-1859, colisionaron el Congreso y la presidencia de Castilla. Incluso, se llegó al intento de vacar la presidencia de la República, por lo que se clausuró el Congreso Extraordinario. El nuevo Congreso de 1860, presidido 
por el obispo Bartolomé Herrera, intentó restablecer los privilegios de la corporación eclesiástica, como lo había planteado en su proyecto constitucional. No obstante, a pesar de su esfuerzo, no lo logró; lo que sí consiguió fue que el gobierno de Castilla entregara rentas estables a la Iglesia.

El discurso de los sectores ultramontanos, como siempre, apuntó a reforzar la presencia de la religión católica en la vida del país, pues así se lograría alcanzar la justicia y la libertad. Por ello, señalaban que la racionalidad del Estado debía estar determinada por el reconocimiento de la Iglesia y sus valores. Esta situación permitiría estabilizar la vida política y social del país; pues la Iglesia era la única institución que podría evitar los abusos y excesos que ocurrían durante las luchas políticas, en las que, generalmente, se abusaba de la idea de libertad. De esta manera, los ultramontanos consiguieron espiritualizar su discurso político, a fin de convertirse en el foco que irradia el orden conservador y la justicia en la República.

Durante la década de 1860, los diferentes discursos civiles, tanto liberales como conservadores, eclesiásticos y ultramontanos, empezaron a agrietar la República corporativa. Como fruto de ello, el militarismo seguiría siendo cuestionado con mayor fuerza y desembocaría, en los años siguientes, en el establecimiento de una República cada vez más racional, con un discurso más civil y de orden. Ello permitiría, finalmente, que el augurio de la Independencia se empiece a hacer realidad en la segunda mitad del siglo xIx.

\section{Referencias}

Del Águila, A. (2013). La ciudadanía corporativa. Política, constituciones y sufragio en el Perú (1821-1896). Lima: Instituto de Estudios Peruanos.

EspinozA, A. (2010). Las instituciones al poder: el aporte de Bartolomé Herrera. En F. Altuve-Febres (comp.), Bartolomé Herrera y su tiempo (pp. 249-265). Lima: Editorial Quinto Reino.

HeRRERA, B. (1860). Proyecto de reforma constitucional. Lima: Imprenta de José Masías.

IBERICO RUIz, R. (2013). La República católica dividida: ultramontanos y liberales regalistas, Lima 1855-1860 (tesis para optar el título de licenciado en Historia). Pontificia Universidad Católica del Perú.

JAMANCA VEGA, M.-A. (2015). La Constitución inacabada. Ideas y modelos constitucionales en el momento fundacional del Perú en la primera mitad del siglo xIx. Lima: Universidad Nacional Mayor de San Marcos.

\section{Bibliografía}

Anónimo. (1858). Observaciones sobre la Constitución de 1856. Necesidad de su reforma. Lima: Imprenta de Manuel Langori.

Anónimo. (1860a). Breves reflexiones sobre el punto capital que debe abrazar la reforma de la Constitución de 1856. Tacna: Imprenta de Andrés Freire.

AnÓNImo. (1860b). El sistema representativo y la cuestión del día. Lima: Establecimiento tipográfico de Aurelio Alfaro.

Anónimo. (1860c). Las constituciones del Perú y la situación actual de esta República. Lima: Imprenta de José María Masías.

Anónimo. (1860d). Opúsculo sobre la necesidad de reformar la Carta fundamental de la República, dada por la Convención Nacional. Cuzco: Imprenta Republicana por Mariano Campos.

Armas Asin, F. (1998). Liberales, protestantes y masones, modernidad y tolerancia religiosa. Lima: Pontificia Universidad Católica del Perú, Centro Bartolomé de Las Casas.

BASADRE. J. (1994). Perú: problema y posibilidad. Ensayo de una síntesis de la evolución histórica del Perú con algunas

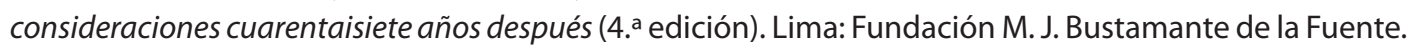


BASADRE, J. (2005). Historia de la República (vol. 4). Lima: Orbis Ventures SAC.

Chambers, S. (2003). De súbditos a ciudadanos: Honor, género y política en Arequipa, 1780-1854. Lima: Red para el Desarrollo de las Ciencias Sociales en el Perú.

ChAnAmÉ, R. (2014). La República inconclusa. Lima: Derrama Magisterial.

Contreras, C., y Cueto, M. (2004). Historia del Perú contemporáneo (3. a ed.). Lima: Instituto de Estudios Peruanos.

Contreras, C., y Zuloaga, M. (2014). Historia mínima del Perú. México D. F.: El Colegio de México.

Gálvez, J.-F. (2010). Herrera y los hermanos Gálvez. En F. Altuve-Febres (comp.), Bartolomé Herrera y su tiempo (pp. 237-248). Lima: Editorial Quinto Reino.

GarCía JoRdÁn, P. (1991). Iglesia y poder en el Perú contemporáneo. Cuzco: Centro Bartolomé de las Casas.

Mesía Ramírez, C. (2012). El pensamiento constitucional y la idea de constitución en el Perú del siglo xix. Revista PUCP. Recuperado de http://revistas.pucp.edu.pe/index.php/pensamientoconstitucional/article/download/ $3253 / 3090$.

Pareja Paz SoldÁn, J. (1943). Historia de las Constituciones nacionales. Lima: Graf. Zenit.

QuiROz CHUECA, F. (2007). Historia del Callao: del puerto de Lima a provincia constitucional. Lima: Gobierno Regional del Callao y Fondo Editorial del Pedagógico San Marcos.

Sobrevilla, N. (2005). El proyecto liberal y la Convención Nacional de 1855. En C. Mc Evoy (Ed.), La experiencia burguesa en el Perú (1840-1940) (pp. 223-243). Madrid-Frankfurt: Iberoamericana-Vervuert.

SobreVILla, N. (2005). Conflicto regional, guano y poder. En P. Drinot y L. Garofalo (Eds.), Más allá de la dominación y la resistencia estudios de historia peruana, siglos XVI-XX (pp. 181-214). Lima: IEP.

SobreVILLA, N. (2009). Batallas por la legitimidad: constitucionalismo y conflicto político en el Perú del siglo XIX (1812-1860). Revista de Indias, LXIX(246), 101-128. 